Article

\title{
Joining of Thermoplastic Composites with Metals Using Resistance Element Welding
}

\author{
Juliane Troschitz $^{1, *}$, Julian Vorderbrüggen ${ }^{2}$, Robert Kupfer ${ }^{1} \oplus$, Maik Gude ${ }^{1}$ \\ and Gerson Meschut ${ }^{2}$ \\ 1 Institute of Lightweight Engineering and Polymer Technology, Technische Universität Dresden, \\ Holbeinstraße 3, 01307 Dresden, Germany; robert.kupfer@tu-dresden.de (R.K.); \\ maik.gude@tu-dresden.de (M.G.) \\ 2 Laboratory for Material and Joining Technology (LWF), Paderborn University, Pohlweg 47-49, \\ 33098 Paderborn, Germany; julian.vorderbrueggen@lwf.upb.de (J.V.); gerson.meschut@lwf.upb.de (G.M.) \\ * Correspondence: juliane.troschitz@tu-dresden.de; Tel.: +49-351-463-38480
}

Received: 30 September 2020; Accepted: 15 October 2020; Published: 16 October 2020

check for updates

\begin{abstract}
Joining is a key enabler for a successful application of thermoplastic composites (TPC) in future multi-material systems. To use joining technologies, such as resistance welding for composite-metal joints, auxiliary joining elements (weld inserts) can be integrated into the composite and used as an interface. The authors pursue the approach of embedding metal weld inserts in TPC during compression moulding without fibre damage. The technology is based on the concept of moulding holes by a pin and simultaneously placing the weld insert in the moulded hole. Subsequently, the composite component can be joined with metal structures using conventional spot welding guns. For this purpose, two different types of weld inserts were embedded in glass fibre reinforced polypropylene sheets and then welded to steel sheets. A simulation of the welding process determined suitable welding parameters. The quality of the joints was analysed by microsections before and after the welding process. In addition, the joint strength was evaluated by chisel tests as well as single-lap shear tests for the different weld insert designs. It could be shown that high-quality joints can be achieved by using the innovative technology and that the load-bearing capacity is significantly influenced by the weld inserts head design.
\end{abstract}

Keywords: multi-material design; thermoplastic composites; joining; resistance spot welding; metal inserts

\section{Introduction}

Thermoplastic composites (TPC) have an important contribution to modern lightweight construction due to their excellent density-related mechanical properties and established efficient production processes [1]. However, one of the obstacles for the use of TPC in multi-material systems is the availability of suitable joining technologies. To increase the efficiency and reduce the complexity, automobile manufactures intend to keep the number of different joining technologies as low as possible [2]. Resistance spot welding is a standardized joining technology, which is widely used for sheet metal structures [2]. Nevertheless, the use of resistance spot welding for multi-material joints is not directly possible due to different physical properties of dissimilar materials, such as melting temperatures and micro-structural incompatibilities [3]. For this reason, various studies address research regarding the welding of dissimilar materials, such as composites or aluminium to steel. The objective is to use conventional spot-welding guns in established metal-oriented processes for composites as well. One approach is to integrate additional metallic elements as joining interfaces. The usage of an auxiliary joining element allows to avoid the welding incompatibility of dissimilar 
materials [4]. These elements can be integrated into composites during or after the part manufacturing process. Joesbury et al. [5] presented a process for thermoset matrix composites based on the integration of a metallic intermediate plate in the joining zone prior to the infiltration process. Subsequently, the weld was created, and finally, the whole assembly was infused with resin. Roth et al. applied a flat weld insert into the composite during preforming, whereby the fibres were displaced by a pin in the welding area [6]. Subsequently, the component was infiltrated in a resin transfer moulding (RTM) process, excluding the welding zone.

An example for the application of additional metallic elements after the composite part manufacturing process is described by Shah et al. [7]. The composite joining part was pre-punched in the flange area and then additional steel doubler strips were positioned on the composite and bonded with adhesive. In the hole area, the additional steel doubler strips were then welded to the metal component creating a form fit between composite and steel. Other studies have investigated the principle of resistance element welding, which was developed for joining high-strength (e.g., ultrahigh-strength steel) and low-ductile materials (e.g., aluminium) in multi-material joints [8]. The additional steel element can be positioned in a pre-hole [9] of the composite component or directly inserted by a punching process and joined to the steel component by resistance welding [10]. Weykenat et al. presented an approach to insert multiple metal layers (multilayer insert) locally into a composite using automated fibre placement [11]. These multilayer inserts lead to a reinforcement of the hole, into which a Flexweld ${ }^{\circledR}$ insert was inserted to join the composite to a steel component by resistance welding [12].

These joining techniques allow the use of conventional spot-welding guns and the integration of composite components in production lines established for metals. Besides, they cause local damage to the reinforcing fibres, which results in reduced load bearing capacity as shown for moulded holes compared to drilled ones [13]. For this reason, Obruch et al. [14] developed a new type of weld insert with a head plate and pins, which is suitable for low-damage integration into thermoplastic composites. Despite the reduction of fibre damage, as no pre-hole is necessary, it has the disadvantage that the embedding of the weld insert is an additional process step. Therefore, the authors pursue a new approach, in which the weld insert is integrated during composite component manufacture in the compression mould without fibre damage.

\section{Materials and Methods}

\subsection{Process-Integrated Embedding of Weld Inserts into TPC}

The technology of process-integrated embedding of weld inserts into TPC uses the principle of moulding holes by a pin tool and simultaneously places weld inserts in the moulded hole [15]. Thereby, the reinforcing fibres are not cut by punching or drilling but shifted aside by a tapered pin tool while the TPC is hot and formable [16]. The integration of the embedding process of the weld inserts into the composite component manufacturing process provides the possibility of reducing the number of process steps and manufacturing costs.

The process is schematically illustrated in Figure 1. At first, a pre-consolidated TPC sheet is warmed up above melting temperature of the matrix polymer by an infrared heating device (Figure 1a). Subsequently, the TPC sheet is transferred into the open compression mould. Immediately after mould closing (Figure 1b), a pin tool is shifted forward, forming a hole by displacing the reinforcing fibres and the still molten thermoplastic matrix (Figure 1c). The pin tool consist of a pin retainer containing a magnet to fix the steel weld insert and the tapered pin. After the pin movement, a ring shaped counterpunch recompresses the squeezed-out material whereby the undercut of the weld insert is filled with fibres and matrix material (Figure 1d). The embedding of the weld insert (steps $\mathrm{c}$ and d) takes less than one second. After cooling and solidification of the TPC specimen, the pin retainer is retracted and the tapered pin is separated. Finally, the TPC specimen with integrated weld insert is demoulded (Figure 1e). 


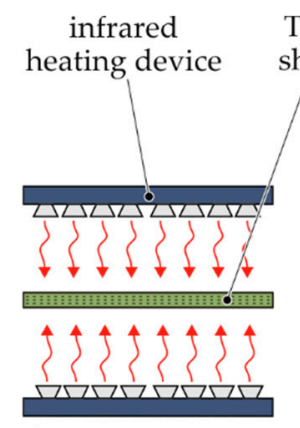

a)

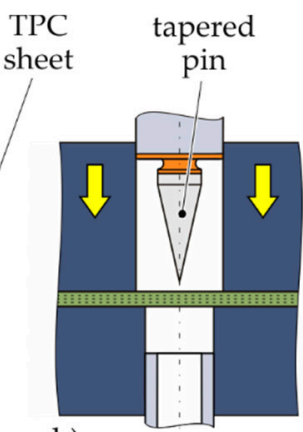

b)

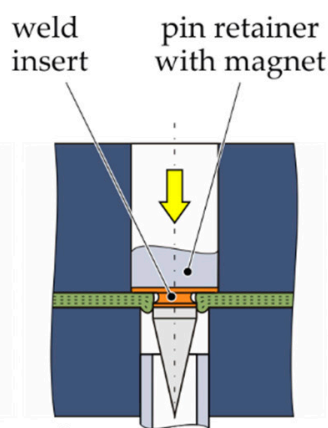

c)

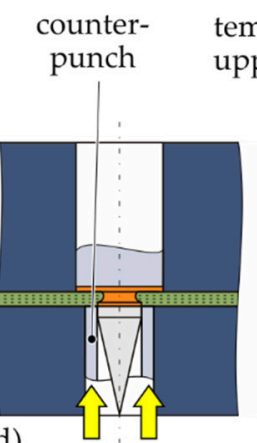

d)

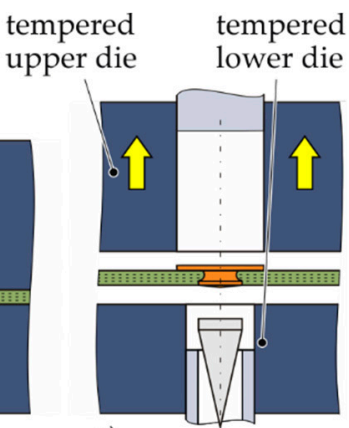

e)

Figure 1. Schematic illustration of process-integrated embedding of weld inserts in thermoplastic composites (TPC): (a) warming up the TPC sheet, (b) closing the compression mould, (c) shifting forward the pin tool, (d) recompressing the squeezed-out material by the counterpunch, (e) demoulding of the TPC specimen.

The process parameters for the embedding of weld inserts in TPC were identified based on the experience of moulding holes [17] and process-integrated embedding of metal inserts into TPC [16]. A tempered steel mould (in this case $40^{\circ} \mathrm{C}$, cf. Table 1) on laboratory scale with vertical flash face is applied to produce plane test specimens with embedded weld inserts. The pin tool is pneumatically actuated, such as the counterpunch. The feed forces have been set at approximately $2.5 \mathrm{kN}$ and $5 \mathrm{kN}$, respectively (cf. Table 1). A schematic illustration of the temperature curve during process-integrated embedding of weld inserts in TPC with the heating temperature of the TPC set to $210^{\circ} \mathrm{C}$ and photos of TPC test specimens with integrated weld inserts are shown in Figure 2.

Table 1. Manufacturing parameters of the process-integrated embedding of weld inserts in TPC.

\begin{tabular}{cc}
\hline Heating temperature TPC & $210^{\circ} \mathrm{C}$ \\
Mould temperature & $40{ }^{\circ} \mathrm{C}$ \\
Moulding pressure & $8 \mathrm{bar}$ \\
Feed force of the pin tool & $2.5 \mathrm{kN}$ \\
Feed force of the counterpunch & $5 \mathrm{kN}$ \\
\hline
\end{tabular}

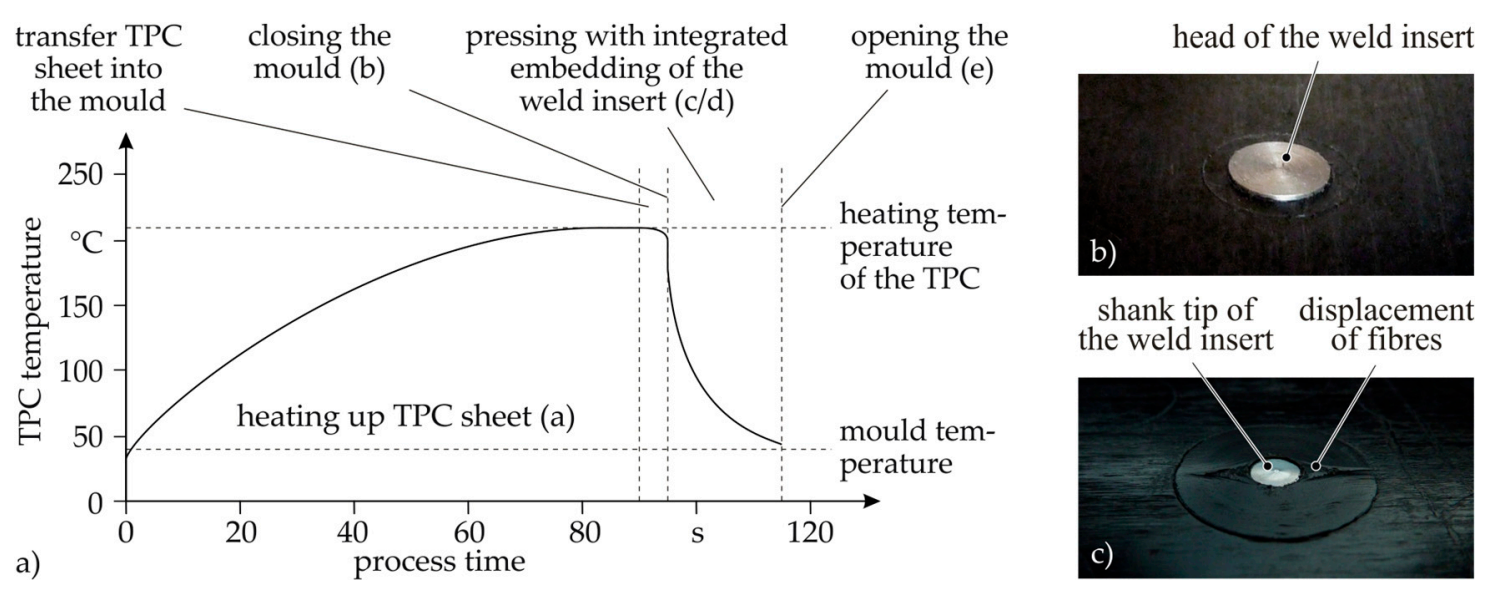

Figure 2. Schematic illustration of the temperature curve during process-integrated embedding of weld inserts in TPC with associated process steps from Figure 1. (a), TPC test specimen with integrated weld insert type A: top view (b) and bottom view (c).

\subsection{Material Specification and Geometry of the Weld Inserts}

The relevant investigations were performed on TPC sheets made of unidirectional glass fibre reinforced polypropylene (GF/PP) tapes, which were produced in an autoclave. GF/PP is a typical material for TPC applications with moderate thermal and mechanical requirements. For example, it is 
used for the large-series production of thermoplastic door module carriers [18]. A low-alloyed steel with high yield strength and a good weldability was chosen for the steel sheet as a typical representative of reinforcement parts e.g., in the automotive industry [19]. A high availability and good weldability are the requirements for the weld insert. An unalloyed structural steel was selected for this purpose. The properties of the TPC as well as the metal sheets and weld inserts used are shown in Table 2. Two different types of weld inserts were embedded in TPC specimens, both rotationally symmetric, see Figure 3. Type A has a head geometry that protrudes from the composite surface as a disturbing contour, whereas type B has a countersunk head and therefore is flush with the composite surface. Both weld inserts have similar shank tips, in order to ensure that the volumes in the welding area are comparable during the welding process.

Table 2. Material specification.

\begin{tabular}{ccc}
\hline TPC & Unidirectional semi-finished product & Celstran ${ }^{\circledR}$ CFR-TP PP-GF70 \\
& Fibre volume content & 45 vol.- $\%$ E-glass \\
& Matrix & Polypropylene $(\mathrm{PP})$ \\
Laminate thickness & $2 \mathrm{~mm}$ \\
Steel sheet & Laminate structure & {$\left[\left(0^{\circ} / 90^{\circ}\right)_{2}\right]_{\mathrm{s}}$} \\
& Material & $\mathrm{HC} 340 \mathrm{LA}([19])$ \\
Weld insert & Sheet thickness & $1.5 \mathrm{~mm}$ \\
& Material & S235JR $([20])$ \\
\hline
\end{tabular}

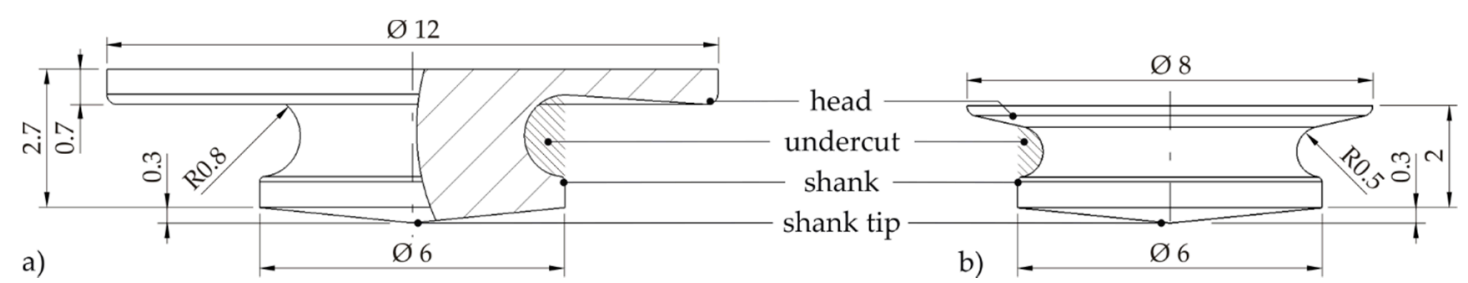

Figure 3. Prototypic weld inserts for process-integrated embedding: (a) type A, (b) type B.

\subsection{Resistance Element Welding (REW)}

After embedding the weld inserts in TPC, experimental investigations regarding resistance element welding were conducted using a powerGUN 2-C type C-frame welding gun by NIMAK International $\mathrm{GmbH}$ (Wissen, Germany). This welding gun has a servomotor drive with a projection of $700 \mathrm{~mm}$ and a maximum electrode force of $8.0 \mathrm{kN}$. The medium-frequency direct current welding device is equipped with a welding case of the type SK-Genius HWI436WA by Harms \& Wende GmbH \& Co. KG (Hamburg, Germany), which has a constant current control and provides a maximum weld current of $65 \mathrm{kA}$. Standardised Electrode caps of type ISO 5821-A0-20-20-100 made from CuCrZr material were used.

The identification of welding areas and the selection of process reliable welding parameters for the qualification of the developed weld inserts were carried out using the numeric simulation software SORPAS ${ }^{\circledR}$ 2D Welding V13.83 Enterprise Edition by SWANTEC Software and Engineering ApS (Kongens Lyngby, Denmark, 2020). In this study the welded joint is created between the isotropic metallic weld insert and a steel sheet. In this regard a two-dimensional, axisymmetric simulation model was built, as shown in Figure 4. The model was built according to the experimental setup. The thermal and the electrical properties of the metallic joining partners and the electrode caps were taken from the SORPAS database. The TPC was modelled in a simplified form as a thermal isotropic material. The electrical resistivity $\left(16 * 10^{15}(\Omega * \mathrm{~cm})\right)$ and the thermal conductivity $(0.69(\mathrm{~W} / \mathrm{m} * \mathrm{~K}))$ of the TPC were adjusted according to the data sheet values. All parts were modelled as deformable bodies with heat conduction. For the mesh, quadrilateral elements (954 elements; 1108 nodes) were used. The associated results are presented in Chapter 3.2. 


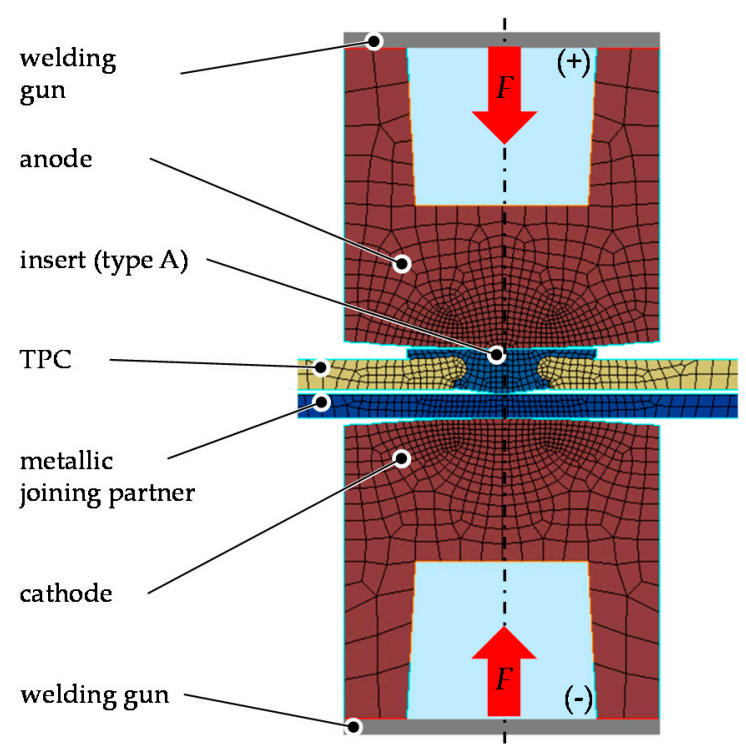

Figure 4. Two-dimensional (2D) axisymmetric model used for the simulation of the resistance element welding process.

\subsection{Mechanical Testing}

Both prototypic weld inserts have a shank with an undercut to prevent the weld insert from falling out when handling the composite component before joining by REW. Push-out tests were carried out on TPC specimens with embedded weld inserts before welding in order to investigate whether the handling strength is guaranteed. For this purpose, the weld inserts were loaded against the embedding direction. The push-out tests were performed on a universal testing machine (see Figure 5a). The size of the TPC test specimens was $100 \times 100 \mathrm{~mm}^{2}$ and the weld inserts were positioned in the centre. The test specimens were clamped between steel plates with a clearance hole diameter of $18 \mathrm{~mm}$. The load was applied to the weld insert by a pressure pin at a constant crosshead velocity of $1 \mathrm{~mm} / \mathrm{min}$.

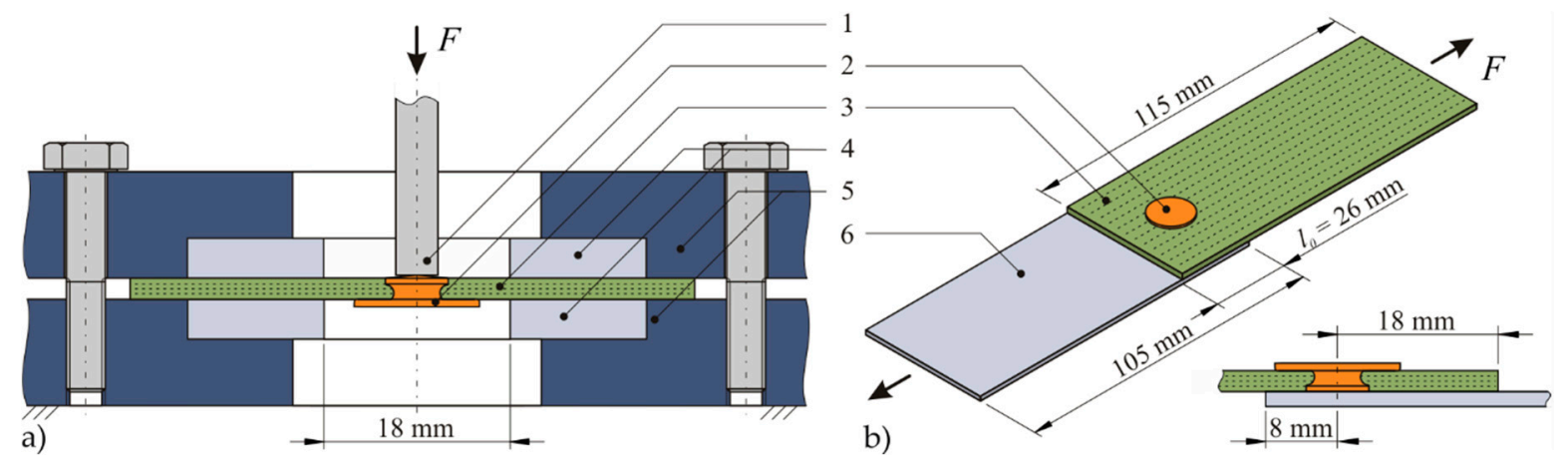

Figure 5. (a) Schematic illustration of the push-out test setup, (b) geometry of single-lap shear specimen ( $l_{0}$ : overlap length); 1 : pressure punch, 2 : weld insert, 3: TPC specimen, 4: exchangeable steel clamping, 5: base steel plates, 6: steel specimen.

After welding the TPC sheets to steel sheets, the welded joints were investigated by chisel tests in accordance with [21] to verify the chosen welding parameters. Chisel test as well as microsections were conducted on quadratic specimen $\left(45 \times 45 \mathrm{~mm}^{2}\right)$ with the weld inserts placed in the centre. Joint strength tests of welded TPC-steel-joints were conducted on single-lap shear specimen in accordance with [22] at quasi-static load. Before welding, the TPC specimen with embedded weld inserts were cut from size $160 \times 100 \mathrm{~mm}^{2}$ to $115 \times 45 \mathrm{~mm}^{2}$. The geometry of the specimen is shown in Figure $5 \mathrm{~b}$. The tests were performed on a high-rigid universal testing machine (Zwick Z100, by ZwickRoell AG, Ulm, Germany) at a testing velocity of $10 \mathrm{~mm} / \mathrm{min}$. The displacement was measured locally in the area of the joint 
using long-stroke extensometers. The extensometers were positioned each at a distance of $22 \mathrm{~mm}$ from the joint centre. The tests ended in the complete separation of the specimen.

\section{Results}

\subsection{Process-Integrated Embedding of Weld Inserts in TPC}

Microscopic examinations of cross sections before REW were carried out to evaluate whether the selected process parameters are suitable for manufacturing high-quality joining zones. As is evident from Figure 6, a complete filling of the undercut with reinforcing fibres and matrix can be achieved for both types of weld inserts. In addition, it is evident that the weld inserts are well positioned with the shank tip protruding from the laminate, thus enabling the welding process. Thus, the selection of the process parameters could be confirmed as suitable for further investigations.

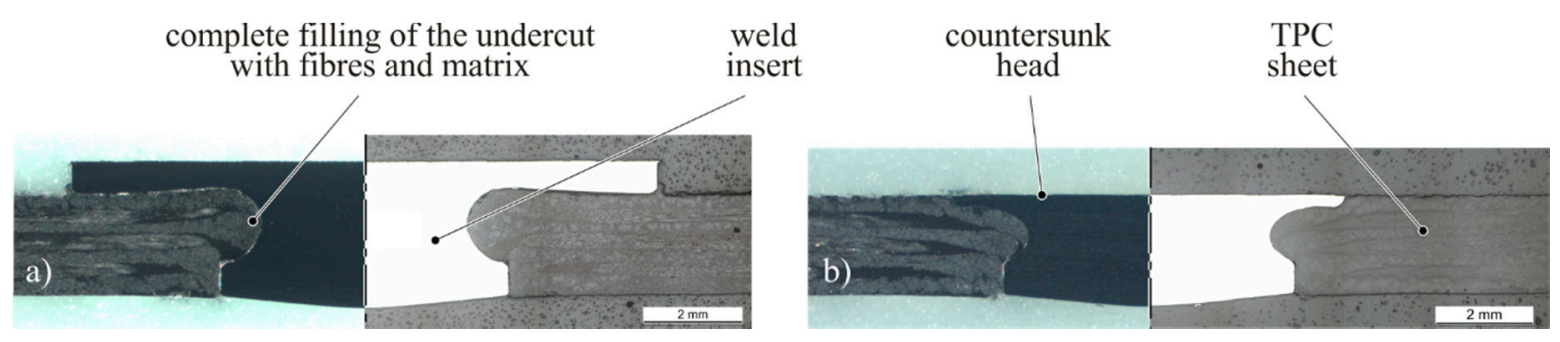

Figure 6. Analysis of the joining zone after embedding: (a) type A, (b) type B.

After qualifying the embedding process by means of microscopic examinations, push-out tests were performed on weld inserts embedded with the selected parameters before REW. The findings are summarised in Figure 7. All load-displacement curves show a progressive initial increase, then an almost linear section before the gradient of the curve declines. From then on, the load increases almost linear up to the maximum push-out force (cf. Figure 7a). The achievable maximum push-out force depends on the weld insert's geometry. In [16] it was demonstrated that the undercut volume has significant influence on the achievable out-of-plane loads for embedded inserts. Weld insert type A has an undercut volume of $16.8 \mathrm{~mm}^{3}$ compared to $6.9 \mathrm{~mm}^{3}$ of type B (cf. Figure 3). Due to the larger undercut, type A with $1.7 \mathrm{kN}$ (arithmetic mean) reaches a higher ultimate push-out load than type B with $0.8 \mathrm{kN}$ (arithmetic mean). For both types of weld inserts, the push-out loads are considered high enough for the further handling process.
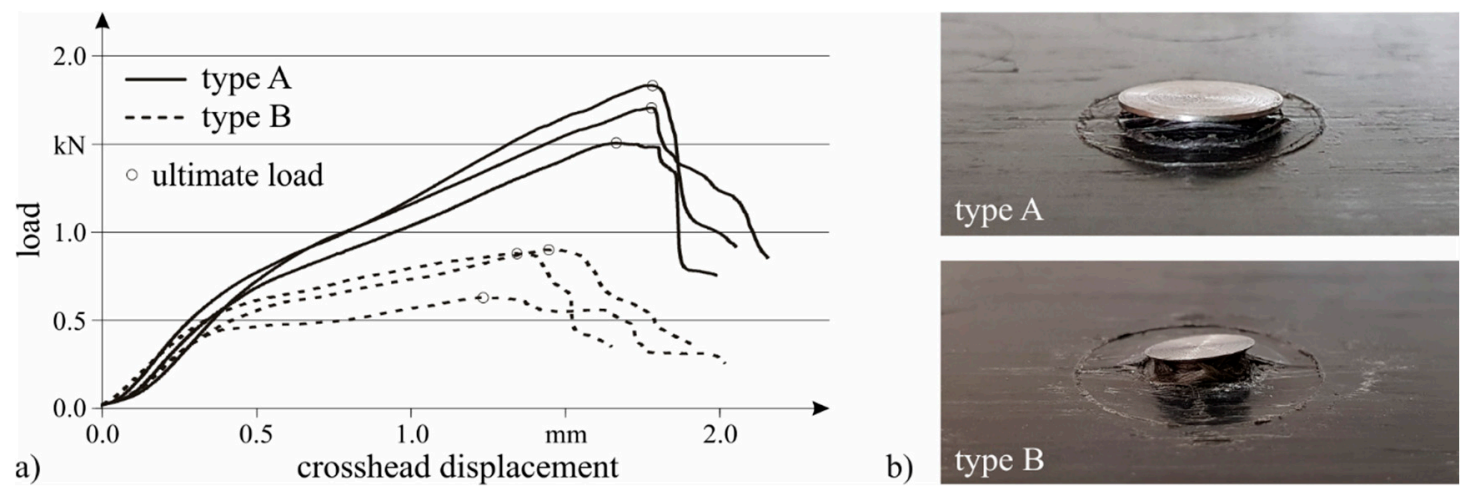

b)

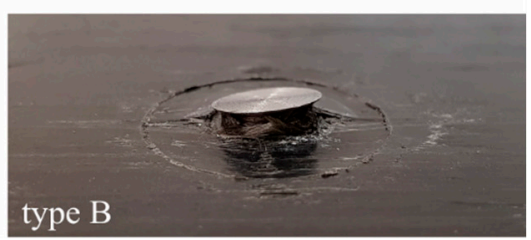

Figure 7. Results of the push-out tests: (a) load-displacement curves, (b) typical failure behaviour.

\subsection{Welding Process Simulation}

After qualifying the embedding of weld inserts in TPC, the aim was to determine suitable welding parameters for resistance element welding of the TPC-steel-joints. To ensure a resource-efficient determination of welding areas and reliable welding parameters for the joints, numeric parameter 
studies were carried out prior the experimental investigations. In order to validate the numeric simulation model, the results of a process simulation were compared to the results of corresponding experimentally welded joints with respect to both the geometry (height and diameter) of the weld nugget and the shape of the heat-affected zone.

Böddeker et al. [23] have reported that for REW of a TPC-steel combination acceptable joints can be provided using electrode caps of the type ISO 58211-A0-20-16-100 and an axial electrode force of $3.0 \mathrm{kN}$. For this reason, similar boundary conditions were selected for this study. For the validation of the simulation model, a weld current of $9.0 \mathrm{kA}$ and a weld time of $60 \mathrm{~ms}$ were chosen. The geometric comparison of the experimental and simulative results as well as the evaluation of the weld nuggets are shown in Figure 8.

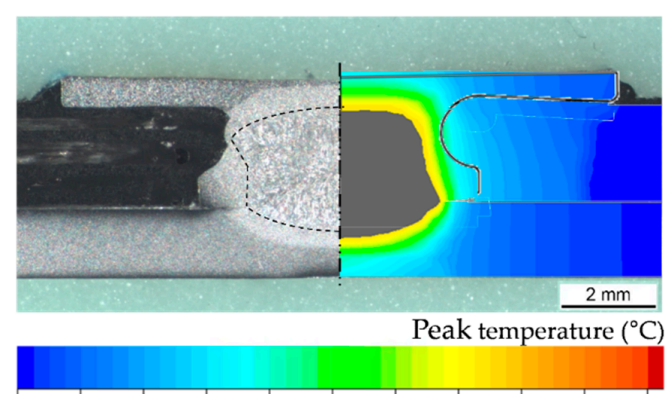

a) $20 \quad 200 \quad 400 \quad 600 \quad 800 \quad 100012001400160018002000$

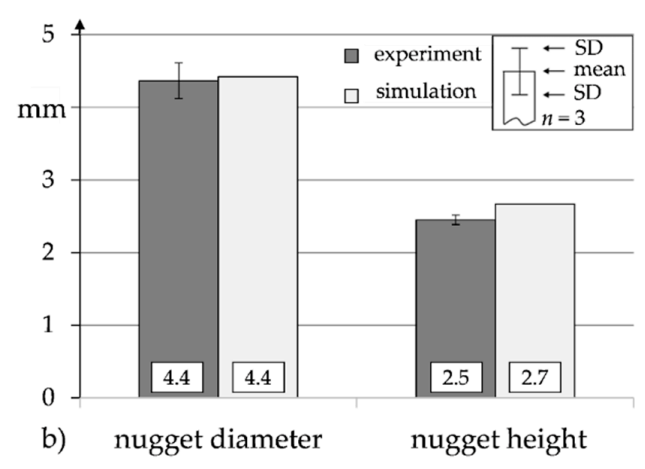

Figure 8. Validation of the welding simulation model via comparison: (a) of the shapes, (b) of the sizes of experimentally and simulatively generated weld nuggets.

By comparing the geometry of the welded area and the heat-affected zone, it can be seen that the process simulation has a good correlation with the experiment. The deviations of the nugget diameter and the nugget height are less than $10 \%$. Therefore, it can be stated that the simulation model ensures a satisfying agreement with the experiments. It can be seen in Figure 8a that the chosen welding parameters lead to a slight deformation of the weld insert in the undercut area. A reason for this phenomena may be a too high thermal energy input during the welding process, which causes a softening of the material in the area of the undercut, where the cross sectional area is minimal. Due to the reduced cross-sectional area, the yield strength of the material is exceeded as a result of the contact pressure of the electrodes, causing the deformation of the weld insert. The thermal energy induced in the weld insert depends on several factors, such as the geometry of the insert, the weld time and weld current, or the electrode force, which has an influence on the contact resistance.

Afterwards, using the optimisation tool available in SORPAS, weld growth curves were generated for discrete weld times in order to define suitable weld current ranges in which appropriate joints can be generated. For this purpose, the weld current $(I)$ was increased in $0.5 \mathrm{kA}$ steps for a given axial electrode force of $3.0 \mathrm{kN}$. Weld times $\left(t_{w}\right)$ were increased in $10 \mathrm{~ms}$ steps in between $40 \mathrm{~ms}$ and $70 \mathrm{~ms}$. For the welding areas, a nugget diameter $\left(d_{n}\right)$ of $3.25 \mathrm{~mm}$ was defined as the lower limit and the occurrence of splashes as the upper limit. Figure 9 shows the weldability lobes for weld insert types A and $\mathrm{B}$ determined by this approach.

According to the results determined by numeric simulation, weldability lobes extending over a range of approximately $2.5 \mathrm{kA}$ (type A) to $3.5 \mathrm{kA}$ (type B) can be expected. With the decreasing weld time, higher currents are required to produce sufficient weld nuggets. At the same time, an extension of the weldability lobes following a reduction of the weld time can be observed, which is consistent with the investigations from [23]. Based on the determined weldability lobes, suitable welding parameters were selected for the subsequent mechanical tests. As Roth et al. [24] showed that for REW short welding times at higher welding currents result in a lower heat input and, consequently, lead to a significantly smaller heat-affected zone, a short weld time is expected to minimise the deformation of the weld insert compared to Figure 8 and the thermal impact of the thermoplastic matrix of the 
TPC. Furthermore, high weld times [23], as well as too high weld currents [25] may lead to thermal damage of resistance element welded polymer-steel-joints. Therefore, a weld time of $40 \mathrm{~ms}$ and a weld current of $11 \mathrm{kA}$ was selected for both types of weld inserts, as this current is located centrally in the determined weldability lobes, thus, ensuring a high level of process reliability.

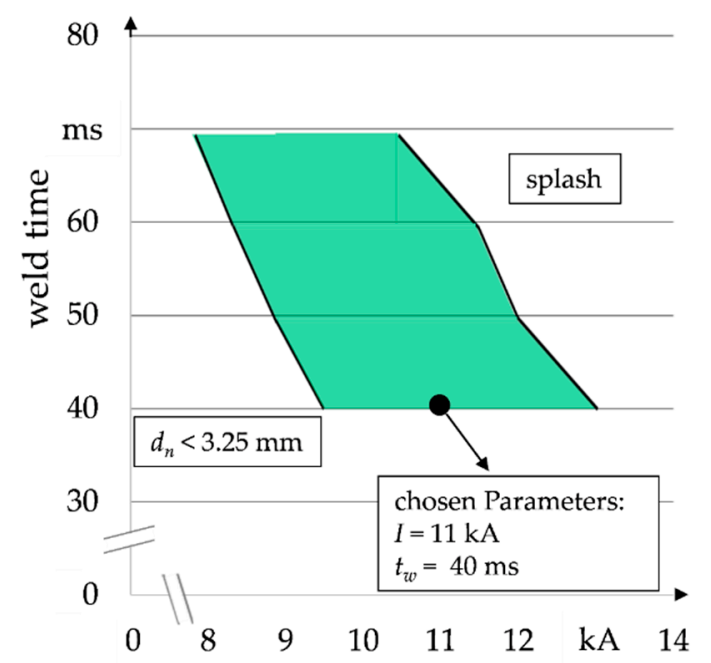

a)

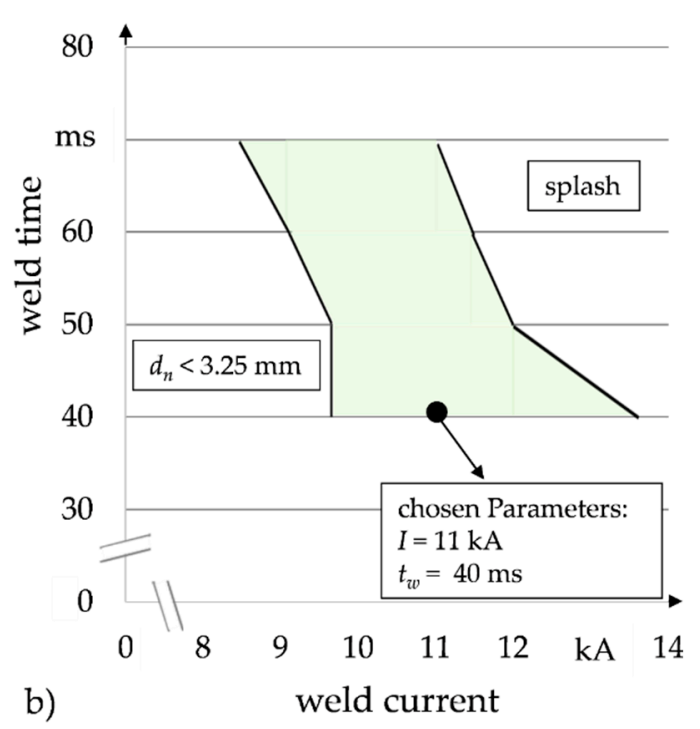

Figure 9. Simulative generated weldability lobes for weld insert type A (a) and type B (b).

\subsection{Mechanical Testing of Welded Joints}

The verification of the selected welding parameters determined by numeric simulation was carried out based on etched microsections for both weld insert types. In addition, chisel tests were conducted, in order to verify a sufficient strength of the weld nugget. In Figure 10, the mentioned microsections and photographs of samples after the chisel tests are shown.
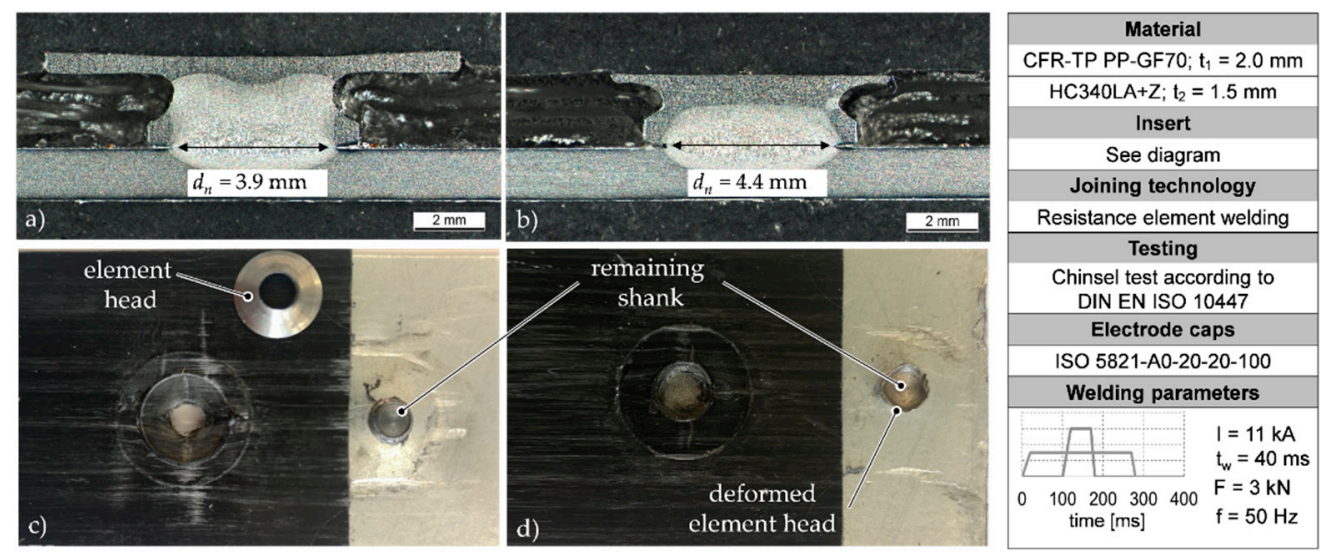

Figure 10. Analysis of the joining zone after resistance element welding (REW) (top: micrographs of welded joints using weld insert type A (a), and type B (b), bottom: pictures of welded specimen using weld insert type A (c) and type B (d) after chisel tests).

For the weld nuggets, diameters of $3.9 \mathrm{~mm}$ (type A) and $4.4 \mathrm{~mm}$ (type B) as well as heights of $1.2 \mathrm{~mm}$ (type A) and $1.3 \mathrm{~mm}$ (type B) were determined. The diameters of the weld nuggets as well as the shape of the heat affected zone are within the range predicted by numeric simulation. With regard to the chisel test, the element heads were peeled off (type A) or deformed (type B). Subsequently, the TPC was unbuttoned, with the weld nugget withstanding. Accordingly, a sufficient strength of the welded joints can be assumed, as the failure mode matches the aspired failure for REW, which is 
unbuttoning of the weld nugget from the base sheet or a head failure, respectively an unbuttoning of the TPC. As the pictures of the chiselled specimen show, no residues of molten plastic or smoke can be seen on the metallic joining partner. Furthermore, as can be seen from the pictures, the plastic matrix of the TPC does not show any thermal damage.

For further investigation of the load-bearing capacity of the joints, shear tests on single-lap joints were carried out under quasi-static load application on five specimens each for both types of weld inserts. The corresponding load-displacement curves, evaluated arithmetic means regarding the ultimate shear loads, the corresponding standard deviations (SD) and exemplary failure pictures of the specimens are shown in Figure 11.
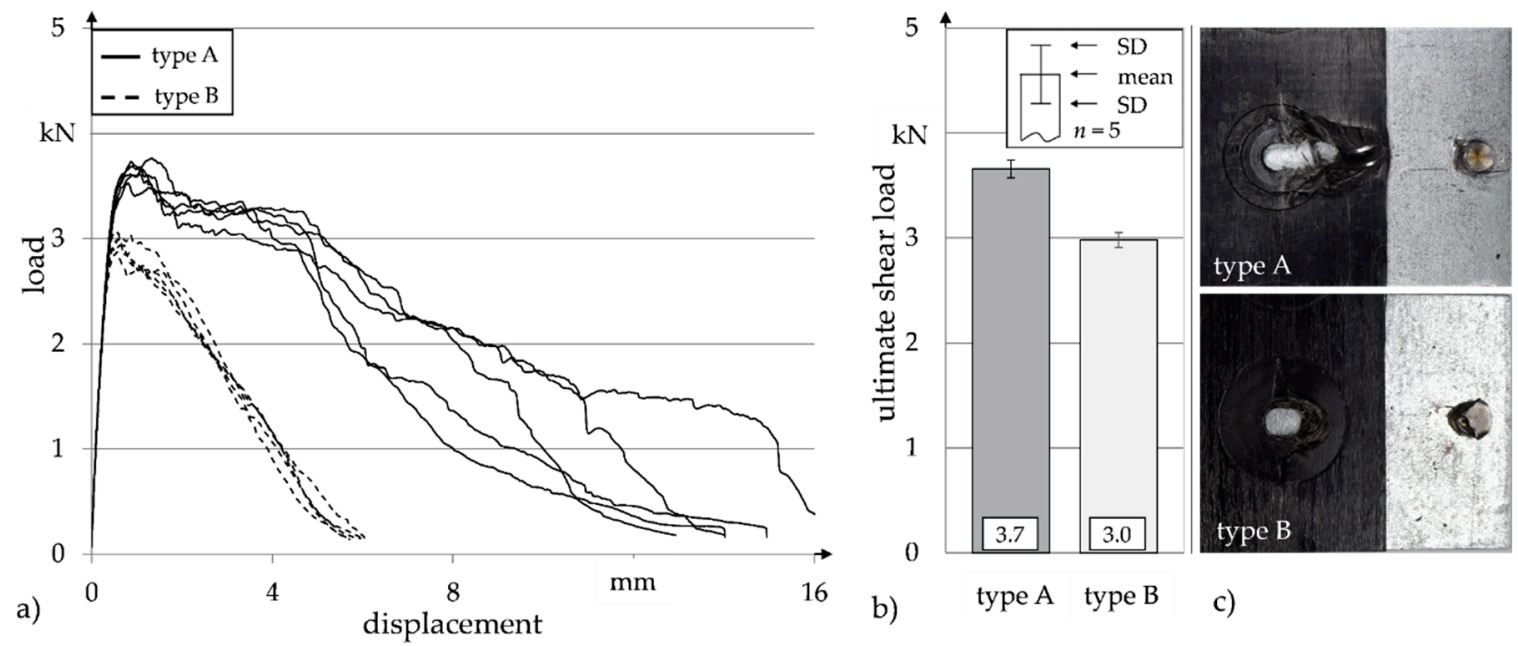

Figure 11. Results of single-lap shear tests under quasi-static load for both types of weld inserts:

(a) load-displacement curves, (b) ultimate shear load, (c) characteristic failure behaviour.

It can be seen that the ultimate shear load of the welded joints using weld insert type A is $3.7 \mathrm{kN}$ on average with a maximum displacement of $13 \mathrm{~mm}$ to $15 \mathrm{~mm}$. The average ultimate shear load of joints using type B weld inserts is significantly lower $(3.0 \mathrm{kN})$ with a maximum displacement of approximately $5 \mathrm{~mm}$ to $6 \mathrm{~mm}$. This phenomenon can be explained by the corresponding failure characteristics. For type A insert, the failure behaviour of the specimens is characterised by the deformation with subsequent peeling off of the element head. Due to the fact that the specimen bend during the shear tests, the joint is loaded with an additional bending moment, which causes the flat head of the weld insert to be deformed before breaking off. Thus a bearing failure in the TPC is induced before the remaining element shank is unbuttoned, which explains the higher load-bearing capacity and in particular the increased displacement at failure. In contrast to that the smaller element head of the type B insert merely deforms during the shear test. Due to the smaller head diameter, the weld insert unbuttons from the TPC at lower load and lower displacement.

Table 3 summarises the mechanical characteristics of embedded weld inserts and welded joints as well as geometric sizes of the weld nuggets for both weld insert types.

Table 3. Mechanical properties of joints and geometric sizes of weld nuggets.

\begin{tabular}{ccc}
\hline Parameter & Type A & Type B \\
\hline push-out load before welding (mean) & $1.7 \mathrm{kN}$ & $0.8 \mathrm{kN}$ \\
nugget height (mean) & $1.2 \mathrm{~mm}$ & $1.3 \mathrm{~mm}$ \\
nugget diameter (mean) & $3.9 \mathrm{~mm}$ & $4.4 \mathrm{~mm}$ \\
ultimate shear load (mean) & $3.7 \mathrm{kN}$ & $3.0 \mathrm{kN}$ \\
\hline
\end{tabular}




\section{Discussion}

Microscopic examinations of cross sections of embedded weld inserts before REW verified a complete filling of the undercut with reinforcing fibres and matrix for both types of weld inserts. Furthermore, the weld inserts are well positioned with the shank tip protruding from the laminate to enable the subsequent welding process. Thus, the selected process parameters for process-integrated embedding of weld inserts into TPC (cf. Table 1) could be confirmed as suitable for further investigations. The developed technology can be applied to other types of TPC in terms of matrix material as well as architecture and material of the reinforcement. For this purpose, the process parameters such as the heating temperature of the TPC sheet and the mould temperature need to be adjusted accordingly.

For an application of the developed technology, especially in series production, the joint strength of the embedded weld inserts and the TPC component must be high enough to provide reliable handling of the component up to the final part assembly by REW. Due to the larger undercut, the measured ultimate push-out load of type A with $1.7 \mathrm{kN}$ is higher than type B with $0.8 \mathrm{kN}$. For the further handling process, the push-out loads are considered high enough for both types of weld inserts.

For the subsequent welding process, suitable process parameters were determined by numeric welding simulations, which were verified by the analysis of etched microsections. The shape and diameter of the weld nuggets were within the range predicted by the numeric simulation. With these types of welding simulations, a prediction of suitable process parameters can be obtained rapidly for applications with alternative materials or sheet thicknesses. In this context, the short welding times of $40 \mathrm{~ms}$ are particularly notable, which promise efficient processing.

In chisel tests, a sufficient strength of the welded joints could be determined, as the failure mode matched the aspired failure for REW, which is unbuttoning of the weld nugget from the steel sheet or unbuttoning of the TPC. Tensile test using a weld stud welded on the head of the insert to transfer the tensile load will be carried out in order to quantify the ultimate strength of the weld nugget between the insert and the steel sheet.

The ultimate shear load of the welded joints is higher for weld insert type $\mathrm{A}(3.7 \mathrm{kN})$ as compared to type $B(3.0 \mathrm{kN})$. This is due to the significantly smaller countersunk head of type B compared to the head geometry of type A that protrudes from the composite surface as a disturbing contour. The load bearing capacity could be further increased by adjusting the head geometry, for example by increasing the head thickness. This could change the failure behaviour under shear load to a laminate bearing before element pull-out of the TPC. In addition, cross-tension tests will be carried out for further evaluation of the load bearing capability.

It could be shown that high-quality joints can be achieved with the developed technology. This provides the opportunity to use conventional spot-welding guns in established metal-oriented processes for TPC as well. Compared to other technologies using weld inserts (such as [14]), the proposed approach allows the embedding of the weld insert during composite component manufacture without an additional process. Thereby the embedding of the weld insert does not require the preparation of a pre-hole in the TPC. For these reasons, the developed technology offers an excellent opportunity to integrate TPC into steel dominated multi-material systems. Of particular interest are fields of application where resistance spot welding is already implemented in series production, such as in the automotive industry.

\section{Conclusions}

TPC components can be welded to steel sheets by using embedded weld inserts as an interface. It could be shown, that weld inserts can be embedded in TPC during compression moulding in high quality and without fibre damage. Push-out tests before REW confirmed that the joint strength is high enough for further handling processes.

For the subsequent welding process, suitable process parameters were determined by numeric welding simulations. The ultimate shear load of the welded joints is significantly dependent on the head design of the embedded weld inserts. By analysing the quality and strength of the joints 
after the different process steps, it could be shown that high-quality joints can be achieved with this innovative technology.

Author Contributions: Process-integrated embedding of weld inserts in TPC, J.T.; analysis of the joint before welding, J.T.; simulation of the welding process and welding, J.V.; mechanical testing of welded joints, J.V.; writing and visualization, J.T. and J.V.; writing-review, R.K., M.G., and G.M.; funding acquisition J.T., J.V., R.K., M.G., and G.M.; project administration, M.G. and G.M. All authors have read and agreed to the published version of the manuscript.

Funding: The research project "Entwicklung multifunktionaler Schnittstellen zum Verbinden von FKV mit Metallen unter Nutzung etablierter Fügeverfahren" of the European Research Association for Sheet Metal Working (EFB) is carried out in the framework of the industrial collective research programme (IGF No. 20870 BG/EFB No. 08/119). It is supported by the Federal Ministry for Economic Affairs and Energy (BMWi) through the AiF (German Federation of Industrial Research Associations eV) based on a decision taken by the German Bundestag.

Conflicts of Interest: The authors declare no conflict of interest.

\section{References}

1. Behrens, B.-A.; Raatz, A.; Hübner, S.; Bonk, C.; Bohne, F.; Bruns, C.; Micke-Camuz, M. Automated Stamp Forming of Continuous Fiber Reinforced Thermoplastics for Complex Shell Geometries. Procedia CIRP 2017, 66, 113-118. [CrossRef]

2. Modi, S.; Stevens, M.; Chess, M. Mixed Material Joining-Advancements and Challenges; Center for Automotive Research: Ann Arbor, MI, USA, 2017.

3. Schmid, D.; Neudel, C.; Zäh, M.F.; Merklein, M. Pressschweißen von Aluminium-Stahl-Mischverbindungen. Lightweight Des. 2012, 5, 14-19. [CrossRef]

4. Meschut, G.; Janzen, V.; Olfermann, T. Innovative and highly productive joining technologies for multi-material lightweight car body structures. J. Mater. Eng. Perform. 2014, 23, 1515-1523. [CrossRef]

5. Joesbury, A.M.; Colegrove, P.A.; Rymenant, P.V.; Ayre, D.S.; Ganguly, S.; Williams, S. Weld-bonded stainless steel to carbon fibre-reinforced plastic joints. J. Mater. Process. Technol. 2018, 251, 241-250. [CrossRef]

6. Roth, S.; Warnck, M.; Coutandin, S.; Fleischer, J. RTM Process Manufacturing of Spot-weldable CFRP-metal Components. Lightweight Des. Worldw. 2019, 5, 18-23. [CrossRef]

7. Shah, B.; Frame, B.; Dove, C.; Fuchs, H. Structural Performance Evaluation of Composite-to-Steel Weld Bonded Joint. In Proceedings of the 10th Annual Automotive Composites Conference and Exhibition, Troy, MI, USA, 15-16 September 2010; pp. 545-561.

8. Holtschke, N.; Jüttner, S. Joining lightweight components by short-time resistance spot welding. Weld. World 2017, 61, 413-421. [CrossRef]

9. Meschut, G.; Hahn, O.; Janzen, V.; Olfermann, T. Innovative joining technologies for multi-material structures. Weld. World 2014, 58, 65-75. [CrossRef]

10. Meschut, G.; Matzke, M.; Hoerhold, R.; Olfermann, T. Hybrid technologies for joining ultra-high-strength boron steels with aluminum alloys for lightweight car body structures. Procedia CIRP 2014, 23, 19-23. [CrossRef]

11. Herwig, A.; Horst, P.; Schmidt, C.; Pottmeyer, F.; Weidenmann, K.A. Design and mechanical characterisation of a layer wise build AFP insert in comparison to a conventional solution. Prod. Eng. 2018, 12, 121-130. [CrossRef]

12. Weykenat, J.; Denkena, B.; Horst, P.; Meiners, D.; Schmidt, C.; Groß, L.; Herwig, A.; Nagel, L.; Serna, J. Local Fiber-Metal-Laminate used as Load Introduction Element for Thin-Walled CFRP Structures. In Proceedings of the 4th International Conference Hybrid 2020 Materials and Structures, Web Conference, Germany, 28-29 April 2020.

13. Hufenbach, W.; Adam, F.; Kupfer, R. A novel textile-adapted notching technology for bolted joints in textile-reinforced thermoplastic composites. In Proceedings of the ECCM, Budapest, Hungary, 6-7 June 2010; pp. 1-9.

14. Obruch, O.; Jüttner, S.; Ballschmiter, G.; Kühn, M.; Dröder, K. Production of hybrid FRP/steel structures with a new sheet metal connecting element. Biul. Inst. Spaw. 2016, 5, 60-66. 
15. Troschitz, J.; Kupfer, R.; Gude, M. Experimental investigation of the load bearing capacity of inserts em-bedded in thermoplastic composites. In Proceedings of the 4th International Conference Hybrid 2020 Materials and Structures, Web Conference, Germany, 28-29 April 2020; pp. 249-254.

16. Troschitz, J.; Kupfer, R.; Gude, M. Process-integrated embedding of metal inserts in continuous fibre reinforced thermoplastics. Procedia CIRP 2019, 85, 84-89. [CrossRef]

17. Kupfer, R. Zur Warmlochformung in Textil-Thermoplast-Strukturen-Technologie, Phänomenologie, Modellierung. Ph.D. Thesis, Technische Universität Dresden, Dresden, Germany, 2016.

18. Cetin, M.; Thienel, M. Large-series Production of Thermoplastic Door Module Carriers. Lightweight Des. Worldw. 2019, 12, 12-17. [CrossRef]

19. DIN EN 10268 Cold Rolled Steel Flat Products with High Yield Strength for Cold Forming-Technical Delivery Conditions; Deutsches Institut für Normung E.V.: Berlin, Germany, 2013.

20. DIN EN 10025-2 Hot Rolled Products of Structural Steels-Part 2: Technical Delivery Conditions for Non-Alloy Structural Steels; Deutsches Institut für Normung E.V.: Berlin, Germany, 2019.

21. DIN EN ISO 10447 Resistance Welding_-Testing of Welds_Peel and Chisel Testing of Resistance Spot and Projection Welds; Deutsches Institut für Normung E.V.: Berlin, Germany, 2015.

22. DVS/EFB 3480-1 Testing of Properties of Joints-Testing of Properties of Mechanical and Hybrid (Mechanical/Bonded) Joints; DVS: Düsseldorf, Germany, 2007.

23. Böddeker, T.; Chergui, A.; Ivanjko, M.; Gili, F.; Behrens, S.; Runkel, D.; Folgar, H. Joining TWIP-TWIP-Steels for Multi-Material Design in Automotive Industry Using Low heat Joining Technologies. In Proceedings of the 6th Fügetechnische Gemeinschaftskolloquium, Munich, Germany, 7-8 December 2016; pp. 77-82. (In German).

24. Roth, S.; Hezler, A.; Pampus, O.; Coutandin, S.; Fleischer, J. Influence of the process parameter of resistance spot welding and the geometry of weldable load introducing elements for $\mathrm{FRP} /$ metal joints on the heat input. J. Adv. Join. Process. 2020, 2, 100032. [CrossRef]

25. Schmal, C.; Meschut, G. Process characteristics and influences of production-related disturbances in resistance element welding of hybrid materials with steel cover sheets and polymer core. Weld. World 2020, 64, 437-448. [CrossRef]

Publisher's Note: MDPI stays neutral with regard to jurisdictional claims in published maps and institutional affiliations.

(C) 2020 by the authors. Licensee MDPI, Basel, Switzerland. This article is an open access article distributed under the terms and conditions of the Creative Commons Attribution (CC BY) license (http://creativecommons.org/licenses/by/4.0/). 